\title{
Effect of MgO Additive on Volumetric Expansion of Self-degradable Cements
}

\author{
Prepared for \\ The U.S. Department of Energy \\ Energy Efîciency and Renewable Energy \\ Geothermal Technologies Program \\ 1000 Independence Avenue SW \\ Washington, D.C. 20585 \\ Prepared by \\ Toshifumi Sugama, John Warren, and Thomas Butcher \\ Sustainable Energy Technologies Department \\ Brookhaven National Laboratory \\ Upton, NY 11973-5000
}

September 2011

Notice: This manuscript has been authored by employee of Brookhaven Science Associates, LLC under Contract No. DE-AC02-98CH 10886 with the U.S.

Department of Energy. The publisher by accepting the manuscript for publication acknowledges that the United States Government retains a non-exclusive, paid-up, irrevocable, world-wide license to publish or reproduce the published form of this manuscript, or allow others to do so, for the United States Government purposes. 


\section{DISCLAIMER}

This work was prepared as an account of work sponsored by an agency of the United States Government. Neither the United States Government nor any agency thereof, nor any of their employees, nor any of their contractors, subcontractors or their employees, makes any warranty, express or implied, or assumes any legal liability or responsibility for the accuracy, completeness, or any third party's use or the results of such use of any information, apparatus, product, or process disclosed, or represents that its use would not infringe privately owned rights. Reference herein to any specific commercial product, process, or service by trade name, trademark, manufacturer, or otherwise, does not necessarily constitute or imply its endorsement, recommendation, or favoring by the United States Government or any agency thereof or its contractors or subcontractors. The views and opinions of authors expressed herein do not necessarily state or reflect those of the United States Government or any agency thereof. 


\begin{abstract}
We identified hard-burned magnesium oxide $(\mathrm{MgO})$ as a suitable expansive additive for improving the plugging performance of self-degradable, temporary sodium silicateactivated slag/Class C fly ash (SSASC) blend cement sealers into rock fractures in Enhanced Geothermal Systems (EGSs). MgO extended the volumetric expansion of sealers during their exposure to a hydrothermal environment at $200^{\circ} \mathrm{C}$ under pressures, ranging from 300 to 1500 psi. A great expansion rate of $19.3 \%$ was observed by adding $3.0 \mathrm{wt} \% \mathrm{MgO}$ under $300 \mathrm{psi}$ pressure, thus promising to plug thoroughly inner fracture. When the pressure was increased from 300 psi to 1500 psi, the expansion rate of cement markedly reduced, corresponding to the formation of crack-free specimens and the improvement of compressive strength. However, with $3.0 \mathrm{wt} \% \mathrm{MgO}$, the specimens still engendered the generation of numerous visual cracks, although they were prepared under a high pressure of 1500 psi. The effective content of $\mathrm{MgO}$ in minimizing and eliminating the generation of cracks was $2.0 \mathrm{wt} \%$, which provided a moderate expansion of $\geq 0.5 \%$. The compressive strength of $2.0 \mathrm{wt} \% \mathrm{MgO}$ specimens made under a pressure of $300 \mathrm{psi}$ rose $~ 1.7$-fold to $4816 \mathrm{psi}$ with an increasing pressure to $1500 \mathrm{psi}$. The in-situ growth of brucite crystal formed by the hydrothermal hydration of $\mathrm{MgO}$ was responsive for such an expansion of the SSASC cement; meanwhile, two crystalline hydrothermal reaction products, $1.1 \mathrm{~nm}$ tobermorite and calcium silicate hydrated (1), contributed to the development of the sealer's compressive strength. Thus, the increasing pressure seems to suppress and control a growth rate of brucite crystal in response to a lower extension of expansion. Furthermore, all MgO-containing SSASC sealers possessed the watercatalyzed self-degradable properties.
\end{abstract}




\section{Introduction}

During wellbore drilling and logging operations in establishing Enhanced Geothermal System (EGS), a considerable attention of the operators was paid to both pre-existing fractures in the well's underground foundation, and to new pressure-generated one. In terms of lost circulation zones, they cause the wastage of a substantial amount of the circulated water-based drilling fluid or mud; thus, these fractures must be plugged or filled with sealing materials to avoid depleting the drilling fluid or mud. When the wellbore construction was completed, one inevitable concern about the sealing materials emplaced in these fractures was that all the sealing materials must disintegrate during the hydraulic-stimulation process to reopen the plugged fractures, and to promote the propagation of reopened fractures. Therefore, the key to success of this material R\&D was to develop water-catalyzed self-degradable sealers. The breakdown of sealers will create multi-fissures and-cracks, allowing the working fluid to pass through them.

In response to this requirement, BNL's researchers developed self-degradable temporary cementitious materials by combining three industrial by-products, granulated blastfurnace slag, and Class C and Class F fly ashes [1,2]. No Ordinary Portland Cement (OPC) was used in this cementitious system. Although these by-products possess a latent pozzolanic property, they do not form cementitious structures without alkali activators. Thus, we employed sodium silicate consisting of 50.5 mol. wt $\% \mathrm{Na}_{2} \mathrm{O}$ and $46.6 \mathrm{~mol}$. wt $\%$ $\mathrm{SiO}_{2}$ as the alkaline activator. Further, the sodium carboxymethyl cellulose (CMC) was incorporated as the self-degradable promoting additive into the dry alkali activator/byproduct mixes.

As detailed in our previous paper [2], the self-degradation of temporary sealer took placed, when the sealers being heated at temperatures of $\geq 200^{\circ} \mathrm{C}$ came in contact with water. We interpreted the mechanism of this water-catalyzed self-degradation as resulting from the in-situ exothermic reactions between the reactants yielded from the hydrolysis of sodium silicate activator and the thermal degradation of the CMC. The magnitude of 
self-degradation depended on the CMC content; its effective content in promising degradation was $\geq 0.7 \%$.

Another important property in designing sealing materials is to assure an expansion in their volume upon exposure to hydrothermal environments at temperatures of $\geq 200^{\circ} \mathrm{C}$. Such a volume expansion of sealers emplaced in the fractures improves their plugging performance as a means of an enhancement of its adherence to an inner surface of fracture: This ensures that the sealers have adequate stability and reliability without their being washed out and removed by a locally disbanded sealer during further drilling operations. The commonest ways to increase the volume of cementitious materials are to utilize the in-situ growth of the crystalline hydration products formed in the cementitious bodies. Among those products, the sulfoaluminate (ettringite )[3,4]-, and $\mathrm{Ca}$ and $\mathrm{Mg}$ oxides[5-9]-based hydration products are well recognized as expandable ones. The crystalline phase representative of first hydration product is ettringite, $3 \mathrm{CaO} \cdot \mathrm{Al}_{2} \mathrm{O}_{3} \cdot \mathrm{CaSO}_{4} \cdot 32 \mathrm{H}_{2} \mathrm{O}$, containing a large volume of water, and it is formed by mixing five starting materials, Portland cement, anhydrous hauyne $\left(3 \mathrm{CaO} \cdot 3 \mathrm{Al}_{2} \mathrm{O}_{3} \cdot \mathrm{CaSO}_{4}\right)$, gypsum $\left(\mathrm{CaSO}_{4}\right)$, quick lime $(\mathrm{CaO})$, and water [10]. However, ettringite displays two major drawbacks in a high temperature environment: One is a delay in its formation at a heating temperature $>70^{\circ} \mathrm{C}$ [11-14]; the other is its hydrothermal decomposition at temperature $>170^{\circ} \mathrm{C}[15]$. Thus, this volume expansion technology was inapplicable for our sealer.

When the $\mathrm{CaO}$ and $\mathrm{MgO}$ expansive additives embedded in Ordinary Portland Cement (OPC) paste are autoclaved, the additive's hydration initiated promptly in an alkaline environment created by the hydrolysis of OPC, thus reflecting the conversion of $\mathrm{Ca}$ and $\mathrm{Mg}$ oxides into crystalline $\mathrm{Ca}$ and $\mathrm{Mg}$ hydroxides. Afterward, the pressure generated by their in-situ growth extends the expansion and swelling of hydrothermally cured OPC. However, in our previous study on the phase identification in autoclaved sodium silicateactivated slag/Class $\mathrm{C}$ fly ash cementitious material [1], we found that all free lime, $\mathrm{CaO}$, present in Class $\mathrm{C}$ fly ash hydrothermally reacted with the slag to form crystalline calcium silicate hydrates, such as calcium silicate hydrate (1) and $1.1 \mathrm{~nm}$ tobermorite. We 
did not detect $\mathrm{Ca}(\mathrm{OH})_{2}$-related crystal phase, which would expand the autoclaved cementitious material. This finding seemingly suggests that $\mathrm{CaO}$ expansive additive might not be useable in the autoclaved sodium silicate-activated slag/Class C fly ash system because of its reactivity with silicate species, instead of the formation of $\mathrm{Ca}(\mathrm{OH})_{2}$.

Based upon the information described above, our interest focused on investigating the usefulness of dead-burned $\mathrm{MgO}$ as an expansive additive for sodium silicate-activated slag/Class C fly ash (SSASC) blend cement. Accordingly, this study centered on the following two major R\&D efforts: First, we explored the compatibility of MgO with the self-degradable SSASC cement; second, we detailed the effectiveness of MgO in extending the rate of expansion of the SSASC cement under the pressure, ranging from 300 to $1500 \mathrm{psi}$. The former involved measuring the compressive strength of $200^{\circ} \mathrm{C}$ autoclaved cements by varying the content of $\mathrm{MgO}$ under four different pressures, 300 , 600,1000 , and $1500 \mathrm{psi}$, respectively. In addition, we assessed whether MgO-modified SSASC cements still can self-degrade. The second effort encompassed measuring the rate of expansion, identifying the hydrothermally hydrated reaction products, and exploring the development of microstructure in the expanded cement.

\section{Experimental Procedure}

Hard burned magnesium oxide (98.3 wt\% $\mathrm{MgO}$ ) under the trade name "MagChem 10 CR" from Martin Marietta Magnesia Specialties, LLC was used as expansive additive. Its physical properties included $97 \%$ passing 200 mesh $(0.074 \mathrm{~mm})$ and surface area ranging

from 0.2 to $0.3 \mathrm{~m}^{2} / \mathrm{g}$. The contents of $\mathrm{MgO}$ additive were $0.5,1.0,1.5,2.0$, and $3.0 \%$ by the total weight of cement components. Two industrial by-products with pozzolanic properties, granulated blast-furnace slag under trade name "New Cem," and Class C fly ash, were used as the hydraulic pozzolana cement. The slag was supplied from Lafarge North America, and fly ash was obtained from Boral Material Technologies, Inc. A sodium silicate granular powder under trade name "Metos Bead 2048," supplied by The PQ Corporation, was used as the alkali activator of these pozzolana cements; its chemical composition was 50.5 mol. wt $\% \mathrm{Na}_{2} \mathrm{O}$ and $46.6 \mathrm{~mol}$. wt $\% \mathrm{SiO}_{2}$. The formula of the dry pozzolana cements had slag/Class C fly ash ratio of $20 / 80$ by weight. Sodium silicate 
powder at $4 \%$ by the total weight of pozzolana cement was added to prepare the dry mix cementitious reactant.

Sodium carboxymethyl cellulose (CMC) was produced by etherification of cellulose from renewable resources, like wood. CMC under the production name "Walocel CRT 30 PA," supplied by Dow Chemical Corp., was used as the thermal degradable additive to promote the disintegration of the slag/Class C fly ash-based sealers; it dissolves in water, forming an anionic polymer. Its content was $0.7 \%$ by total weight of dry slag/Class $\mathrm{C}$ fly ash/sodium silicate activator mixture.

The sodium silicate-activated slag/Class C fly ash (SSASC) slurries together with CMC and $\mathrm{MgO}$ were prepared by adding an appropriate amount of water to the dry mix cementitius component, and then left them in an atmospheric environment until the cement set. Afterward, all SSASC samples were exposed in an autoclave at $200^{\circ} \mathrm{C}$ for 5 hours under $300,600,1000$, and 1500 psi pressures; some autoclaved samples then were heated for 24 hours in an oven at $200^{\circ}$ and $250^{\circ} \mathrm{C}$.

\section{Measurements}

To measure the expansion rate, the MgO-containing SSASC slurries were cast in molds, $35 \mathrm{~mm}$ diameter $\times 70 \mathrm{~mm}$ length, and then left at room temperature for 20 hours to solidify. After removing the material from the molds, we measured their initial diameter. Then, the specimens were exposed in an autoclave at $200^{\circ} \mathrm{C}$ for 5 hours under the pressure of $300,600,1000$, and $1500 \mathrm{psi}$, respectively, followed by measuring the diameter of the expanded specimens. Some of these autoclaved specimens were used for determining compressive strength testing. X-ray powder diffraction (XRD) was used to identify the crystalline hydrothermal reaction products formed in these autoclaved samples. The high-resolution scanning electron microscopy (HR-SEM) was employed to explore the morphologies of the crystalline hydrothermal reaction products in SSASC cement. To identify these reaction products, we used energy-dispersible $\mathrm{x}$-ray (EDX) concomitant with HR-SEM. 
With a Type $\mathrm{K}$ thermometer, in conjunction with temperature data logger, we monitored the heat energy generated in a self-degrading process of the $200^{\circ}$ - and $250^{\circ}$-heated SSASC specimens after their contact with water.

\section{Results and Discussion}

\section{Expansion}

Figure 1 plots the changes in expansion rate of sodium silicate-activated slag/Class $\mathrm{C}$ fly ash (SSASC) cement as a function of $\mathrm{MgO}$ content under the pressure of $300 \mathrm{psi}$. The data clearly revealed the effectiveness of $\mathrm{MgO}$ in extending the expansion of the specimens after autoclaving; in fact, the expansion rate rose with an increasing content of $\mathrm{MgO}$. Thus, with $1.5 \% \mathrm{MgO}$, the expansion rate of $1.09 \%$ was $\sim 14$ fold higher than that of the specimens without $\mathrm{MgO}$. Further incorporation of $\mathrm{MgO}$ to $2.0 \%$ led to a high expansion rate of $3.8 \%$, corresponding to the generation of numerous cracks in such specimens. The striking swelling was observed from $3.0 \% \mathrm{MgO}$, reflecting a considerably high expansion rate of $19.3 \%$ (Fig.1).

Our focus next centered on monitoring the changes in the expansion rate of 2.0 and $3.0 \%$ $\mathrm{MgO}$-incorporated SSASC specimens by varying the pressure, ranging from 300 to 1500 psi (Figure 2). For both the 2.0 and $3.0 \% \mathrm{MgO}$ specimens, the resulting data revealed that the expansion rate declined with the increase in pressure. With $3.0 \% \mathrm{MgO}$, increasing the pressure to $600 \mathrm{psi}$ from $300 \mathrm{psi}$ conspicuously reduced its rate to $9.5 \%$ from $19.3 \%$. A further increase in pressure to 1000 psi provided a minimum expansion of $2.7 \%$. A similar expansion rate was detected from the specimens made under 1500 psi pressure, seemingly suggesting that the pressures between 1000 and $1500 \mathrm{psi}$ had no significant effect on suppressing the expansion of SSASC. As is evident from the photos in Figure 2, although the rate of expansion was minimized by a high pressure at 1000 and $1500 \mathrm{psi}$, we visually observed the development of some cracks in the specimens. In contrast, no visual cracks were reported in the $2.0 \% \mathrm{MgO}$-incorporated specimens made under pressures of $\geq 600$ psi. Thus, an effective amount of $\mathrm{MgO}$ in creating a crack-free SSASC along with a moderate rate of expansion is likely to be $2.0 \%$. 


\section{Compressive strength}

Figure 3 plots the compressive strength vs. MgO content for SSASC specimens after being autoclaved for 5 hours at $200^{\circ} \mathrm{C}$ and at 300 psi pressure. In this test series, no compressive test was made for $3.0 \% \mathrm{MgO}$ specimen because its exceeding expansion caused difficulty in conducting compressive strength. The resulting data showed that adding a proper amount of $\mathrm{MgO}$ offered improved compressive strength, compared with strength of 2537 psi in the specimens without MgO: The highest strength level of 4739 psi was recorded from the specimens containing $1.0 \% \mathrm{MgO}$. This information denoted that the expansion of SSASC specimens modulated by $\mathrm{MgO}$ was responsible for improving the compressive strength. However, adding 1.5 and $2.0 \% \mathrm{MgO}$ reduced compressive strength to 3690 and 2844 psi, seemingly suggesting that some fissures and cracks generated by an excessive content of $\mathrm{MgO}$ affected a decline of its strength.

Our attention next shifted to investigating the changes in compressive strength brought about by increasing hydrothermal pressure. To obtain this information, $2.0 \% \mathrm{MgO}$ containing specimens were prepared in $200^{\circ} \mathrm{C}$ autoclave under 600,1000 and $1500 \mathrm{psi}$ pressures. We then determined their compressive strengths (Figure 4). As expected, the increase in pressure offered improved compressive strength; namely, the strength value of 2844 psi for 300 psi pressure-made specimens rose $\sim 1.7$-fold to $4816 \mathrm{psi}$, when it was prepared under 1500 psi pressure. Conceivably, such an improved compressive strength by a high pressure may be due to the following two factors: One is an enhancement in the hydration rate of SSASC; the other is related to an alteration in a densified cementitious structure.

\section{Phase Identification SEM Exploration}

The XRD studies were undertaken to identify the crystalline hydration reaction products contributing to the extension of volumetric expansion and the development of compressive strength for $\mathrm{MgO}$-incorporated SSASC specimens after $200^{\circ} \mathrm{C}$ autoclaving.

Figure 5 depicts the XRD tracings, ranging from 5 to 51 (29, degree), for SSASC specimens containing $0,1,2$, and $3 \% \mathrm{MgO}$, respectively. For the specimens without 
$\mathrm{MgO}$, the XRD pattern (a) revealed the formation of two hydrothermal-catalyzed pozzolanic reaction products, $1.1 \mathrm{~nm}$ tobermorite $\left[\mathrm{Ca}_{5}(\mathrm{OH})_{2} \mathrm{Si}_{6} \mathrm{O}_{16} .5 \mathrm{H}_{2} \mathrm{O}\right]$ phase and the calcium silicate hydrate (I) $\left[\mathrm{CaO} \cdot \mathrm{SiO}_{2} \cdot \mathrm{H}_{2} \mathrm{O}, \mathrm{C}-\mathrm{S}-\mathrm{H}\right.$ (I) $]$ phase. The other phases detected, such as quartz and tricalcium aluminate $\left(3 \mathrm{CaO} . \mathrm{Al}_{2} \mathrm{O}_{3}, \mathrm{C}_{3} \mathrm{~A}\right)$, were associated with the non-reacted Class $\mathrm{C}$ fly ash and slag as the starting materials. The specimens containing $1.0 \% \mathrm{MgO}$ showed similar feature in XRD patter (b), except for the presence of brucite $\left[\mathrm{Mg}(\mathrm{OH})_{2}\right]$ yielded by the hydrothermal reaction of $\mathrm{MgO}$. The XRD line intensity of the brucite-related $d$ spacings rose with an increasing content of $\mathrm{MgO}$, while the quantity of the other reaction products and the non-reaction ones remained unchanged. Thus, the insitu phase transformation of $\mathrm{MgO}$ to $\mathrm{Mg}(\mathrm{OH})_{2}$ in an autoclave at $200^{\circ} \mathrm{C}$ appears to serve in expanding and swelling the cementitious specimens.

To visualize the alteration of microstructure caused by in-situ $\mathrm{MgO} \rightarrow \mathrm{Mg}(\mathrm{OH})_{2}$ phase transition, we compared the fracture surfaces of $0.0 \%$ and $3.0 \% \mathrm{MgO}$-containing SSASC specimens after autoclaving at $200^{\circ} \mathrm{C}$, by SEM-EDX (Figure 6). The SEM image of specimen without $\mathrm{MgO}$ revealed the growth of fiber-like crystals as the hydration products. The EDX analysis of these crystals exhibited that they encompasses three major elements, O, Ca, and $\mathrm{Si}$, attributed to a possible tobermorite and C-S-H (1) crystals. The other atoms, such as $\mathrm{Na}, \mathrm{Mg}$, and $\mathrm{Al}$, may come from the non-reacted slag, Class $\mathrm{C}$ fly ash and sodium silicate activator. In contrast, a quite different image was observed from the $3.0 \% \mathrm{MgO}$ specimen. This image was characterized by a radical growth of sunflower-like crystals. As is seen in the EDX atomic composition for these crystals, there were two major elements, $\mathrm{O}$ and $\mathrm{Mg}$, strongly suggesting that this morphology can account for being a well-formed crystal structure of brucite, $\mathrm{Mg}(\mathrm{OH})_{2}$ contributing to the volumetric expansion of sealer.

\section{Self-degradation}

To ensure that $\mathrm{MgO}$ does not prohibit the self-degradation of sealer, our focus next centered on visualizing the self-degradation of SSASC sealers containing 0,0.5, 1.0, and $2.0 \% \mathrm{MgO}$. To do so, we adapted the same experimental method as that of our previous work on the slag/Class $\mathrm{C}$ fly ash system. The detailed test procedures were as follows; 1) 
the specimens were autoclaved at $200^{\circ} \mathrm{C}$ for 5 hours under 300 psi pressure, and then heated at $200^{\circ}$ and $250^{\circ} \mathrm{C}$ for 24 hours, 2) the specimens were cooled for 24 hours at room temperature, 3 ) thermocouple-embedded specimens were placed in a vacuum chamber at $-1000 \mathrm{kPa}$ for $10 \mathrm{~min}$ to eliminate any air present in the specimens, 4) air-free voids in the vacuumed specimens were filled with water (water/specimens volume ratio= 17/1), while determining the generation of in-situ exothermic heat by temperature data logger, and 5) visual observation was made to evaluate the magnitude of self-degradation.

For $200^{\circ} \mathrm{C}$-heated specimens, Figure 7 plots the in-situ exothermic temperature generated in the vacuumed SSASC specimens as a function of elapsed time after they were impregnated with water. In the specimens without $\mathrm{MgO}$, the resulting temperature-time relation cure showed that $\sim 75 \mathrm{sec}$ after impregnating the specimen with water, its internal temperature rapidly rose from $21.9^{\circ} \mathrm{C}$ to a peak of $36.0^{\circ} \mathrm{C}$. The total elapse time from the onset to the maximum temperature was only $238 \mathrm{sec}$. We observed the development of numerous cracks in the water-impregnated specimens along with the increase in their exothermic temperature. Hence, the penetration of water through the specimen led to the evolution of in-situ exothermic heat promoting the self-degradation of the sealer. Although the similar feature of curve was recorded in the $0.5 \% \mathrm{MgO}$ specimen, its peak temperature was $2^{\circ} \mathrm{C}$ lower than that of $0 \% \mathrm{MgO}$. A further drop of peak temperature was observed as more $\mathrm{MgO}$ was added to the SSASC, from $34.0^{\circ} \mathrm{C}$ for $0.5 \% \mathrm{MgO}$ to $28.8^{\circ} \mathrm{C}$ for $2.0 \% \mathrm{MgO}$. Since the addition of $\mathrm{MgO}$ not only extended the rate of volumetric expansion, but also generated cracks in the cement; in fact, numerous cracks were apparent in the $2.0 \% \mathrm{MgO}$ specimens. This fact seemingly suggested that although we did not see any cracks with naked eye in the 0.5 and $1.0 \% \mathrm{MgO}$ specimens, some non-visual cracks might well be there. Assuming this is correct, some of the total exothermic heating energy generated in the specimens might be lost thought pre-existing cracks. Such a loss in heat may account for the reduction of exothermic peak temperature; in fact, the $2.0 \% \mathrm{MgO}$ specimens with their large open cracks resulted in more loss energy, compared with that of the specimens containing less $\mathrm{MgO}$. 
Similar results were obtained from the $250^{\circ} \mathrm{C}$-heated specimens (Figure 8). As is seen, the exothermic peak temperature tended to decrease with an increasing content of $\mathrm{MgO}$, from $44.8^{\circ} \mathrm{C}$ for $0 \% \mathrm{MgO}$ to $32.7^{\circ} \mathrm{C}$ for $2 \% \mathrm{MgO}$. One difference between these and the $200^{\circ} \mathrm{C}$-heated specimens was that the exothermic peak temperature of all $250^{\circ} \mathrm{C}$ specimens was higher than that of the $200^{\circ} \mathrm{C}$ specimens. This fact was interpreted in our previous paper [2]. One pivotal element governing self-degradation was the amount of $\mathrm{CO}_{2}$ and $\mathrm{CH}_{3} \mathrm{COOH}$ as the gaseous by-products emitted by the thermal decomposition of CMC. A large volume of these by-products emitted in an aqueous medium would generate more exothermic heat due to the interactions between the carbonate or sodium hydroxide and $\mathrm{CH}_{3} \mathrm{COOH}$. Thus, the heat treatment at $250^{\circ} \mathrm{C}$ evolved additional amount of these reactive gaseous by-products, compared with that at $200^{\circ} \mathrm{C}$. This was the major reason why the $250^{\circ} \mathrm{C}$-treated specimens had a higher exothermic peak temperature than that of $200^{\circ} \mathrm{C}$. Nevertheless, all the $200^{\circ}$ and $250^{\circ} \mathrm{C}$-heated specimens were selfdegraded, verifying that $\mathrm{MgO}$ had no affection in inhibiting and retarding the selfdegradation activity of SSASC specimens:

\section{Conclusion}

For aim at improving the adherence of a sodium silicate-activated slag/Class $\mathrm{C}$ fly ash (SSASC) blend cement sealing materials to the inner rock fracture in geothermal wells, we evaluated the potential of hard-burned magnesium oxide $(\mathrm{MgO})$ powder in extending the volumetric expansion of this sealer under hydrothermal conduction at $200^{\circ} \mathrm{C}$ under pressure of 300,600, 1000 and 1500 psi, respectively. Also, our evaluation included assessing whether $\mathrm{MgO}$ changes the sealer's compressive strength due to the different

hydrothermal reaction products formed in the cement under pressures, ranging from 300 to 1500 psi. Additionally, we investigated the water-catalyzed self-degradation properties of this sealer. The $\mathrm{MgO}$ additive was transformed into brucite $\left[\mathrm{Mg}(\mathrm{OH})_{2}\right]$ crystal during the hydrothermal exposure of cement. Then the in-situ growth of brucite crystal contributed significantly to the expansion of cement, while the hydration reaction products, crystalline $1.1 \mathrm{~nm}$ tobermorite and calcium silicate hydrate (1), were responsible for strengthening the cement. 
The addition of $2.0 \mathrm{wt} \% \mathrm{MgO}$ led to an extensive expansion of $3.8 \%$, reflecting the development of numerous cracks. Further its incorporation to $3.0 \%$ corresponded to a considerable expansion of $19.3 \%$. The content of $\mathrm{MgO}$, ranging from 0.5 to $1.5 \%$, acted to improve the compressive strength by 1.5- to 1.9-fold, compared with that of the specimens without $\mathrm{MgO}$. This finding suggested that an appropriate expansion serviced in enhancing the sealer's strength. On the other hand, the increase in hydrothermal pressure reduced the expansion rates form $19.3 \%$ at 300 psi to $2.1 \%$ at 1500 psi for 3.0 $\% \mathrm{MgO}$-containing SSASC specimens and from $3.8 \%$ at 300 psi to $0.5 \%$ at 1500 psi for $2.0 \% \mathrm{MgO}$ specimens. Since the expansion rate of sealers depended on the extent of in-

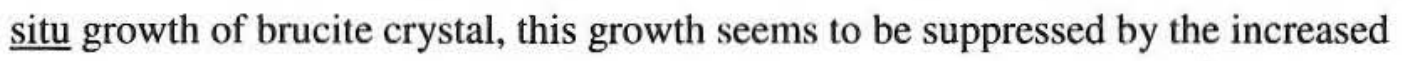
pressure in response to a low rate of expansion. No visual cracks were observed from the $2.0 \% \mathrm{MgO}$ specimens made under pressure of $\geq 600 \mathrm{psi}$. In contrast, the $3.0 \% \mathrm{MgO}$ specimens generated cracks, although they were prepared at a high pressure of 1500 psi. As expected, reducing the expansion rate led to the increase in compressive strength. For instance, with $2.0 \% \mathrm{MgO}$, the compressive strength of 2844 psi developed at $300 \mathrm{psi}$ rose $\sim 1.7$-fold to $4816 \mathrm{psi}$ as the pressure was increased to $1500 \mathrm{psi}$. Nevertheless, the effective content of $\mathrm{MgO}$ in minimizing and eliminating the generation of cracks along with a moderate expansion rate of $\geq 0.5 \%$ was $2.0 \mathrm{wt} \%$.

Although the open fissures created by the expansion of the cement engendered a loss in in-situ exothermic heating energy during water-catalyzed self-degradation processes, all specimens containing MgO were able to disintegrate the SSASC cements. The integration

of all this information strongly verified that $\mathrm{MgO}$ has a high potential as an expansive additive offering an improved plugging performance of self-degradable temporary SSASC sealing materials.

\section{References}

1. T. Sugama, T. Butcher, L. Brothers, and D. Bour "Self-degradable cementitious sealing materials," BNL-94308-2010-IR, October 2010. 
2. T. Sugama, T. Butcher, L. Brothers, and D. Bour "Self-degradable slag/Class F fly ash-blend cements," BNL-94911-2010-IR, March 2011.

3. I. Teoreanu and C. Dumitrescu, "Mechanisms of controlled expansion cements hardening," Cem. Concre. Res., 12 (1982) 141-155.

4. Y. Fu, P. Gu, P. Xie, and J.J. Beaudoin, "Effect of chemical admixtures on the expansion of shrinkage-compensating cement containing a pre-hydrated high alumina cement-based expansive additive," Cem. Concre. Res., 25 (1995) 29-38.

5. S. Chatterji, "Mechanism of expansion of concrete due to the presence of deadburnt $\mathrm{CaO}$ and MgO," Cem. Concre. Res., 25 (1995) 51-56.

6. T. Liang and T. Mingshu, "Correlation between reaction and expansion of alkalicarbonate reaction," Cem. Concre. Res., 25 (1995) 470-476.

7. Y. Qing, C. Huxing, W. Yuqing, W. Shangxian, and L. Zonghan, "Effect of MgO and gypsum content on long-term expansion of low heat portland slag cement with slight expansion," Cem. Concre. Comp., 26 (2004) 331-337.

8. C. Maltese, C. Pistolesi, A. Lolli, A. Bravo, T. Cerulli, and D. Salvioni, "Combined effect of expansive and shrinkage reducing admixtures to obtain stable and durable mortars," Cem. Concre. Res., 35 (2005) 2244-2251.

9. L. Mo, M. Deng, and M. Tang, "Effects of calcination condition on expansion property of $\mathrm{MgO}$-type expansive agent used in cement-based materials," Cem. Concre. Res., 40 (2010) 437-446.

10. S. Nagataki and H. Gomi, "Expansive admixtures (mainly ettringite)," Cem. Concre. Res., 20 (1998) 163-170.

11. R. Yang, C.D. Lawrence, C.J. Lynsdale, and J.H. Sharp, "Delayed ettringite formation in heat-cured Portland cement mortars," Cem. Concre. Res., 29 (1999) $17-25$.

12. P. Yand and X. Qin, "The effect of expansive agent and possibility of delayed ettringite formation in shrinkage-compensating massive concrete," Cem. Concre. Res., 31 (2001) 335-337.

13. T. Ramlochan, M.D.A. Thomas, and R.D. Hooton, "The effect of pozzolans and slag on the expansion of mortars cured at elevated temperature Part II: 
Microstructural and microchimical investigations,” Cem. Concre. Res., 34 (2004) 1341-1356.

14. R. Barbarulo, H. Peycelon, S. Prene, and J. Marchand, "Delayed ettringite formation symptoms on mortars induced by high temperature due to cement heat of hydration or later thermal cycle," Cem. Concre. Res., 35 (2005) 125-131.

15. N. Meller, K. Kyritsis, and C. Hall, "The hydrothermal decomposition of calcium monosulfoaluminate 14-hydrate to katoite hydrogarnet and $\beta$-anhydrite: An insitu synchrotron X-ray diffraction study,” J. Solid State Chem., 182 (2009) 27432747. 


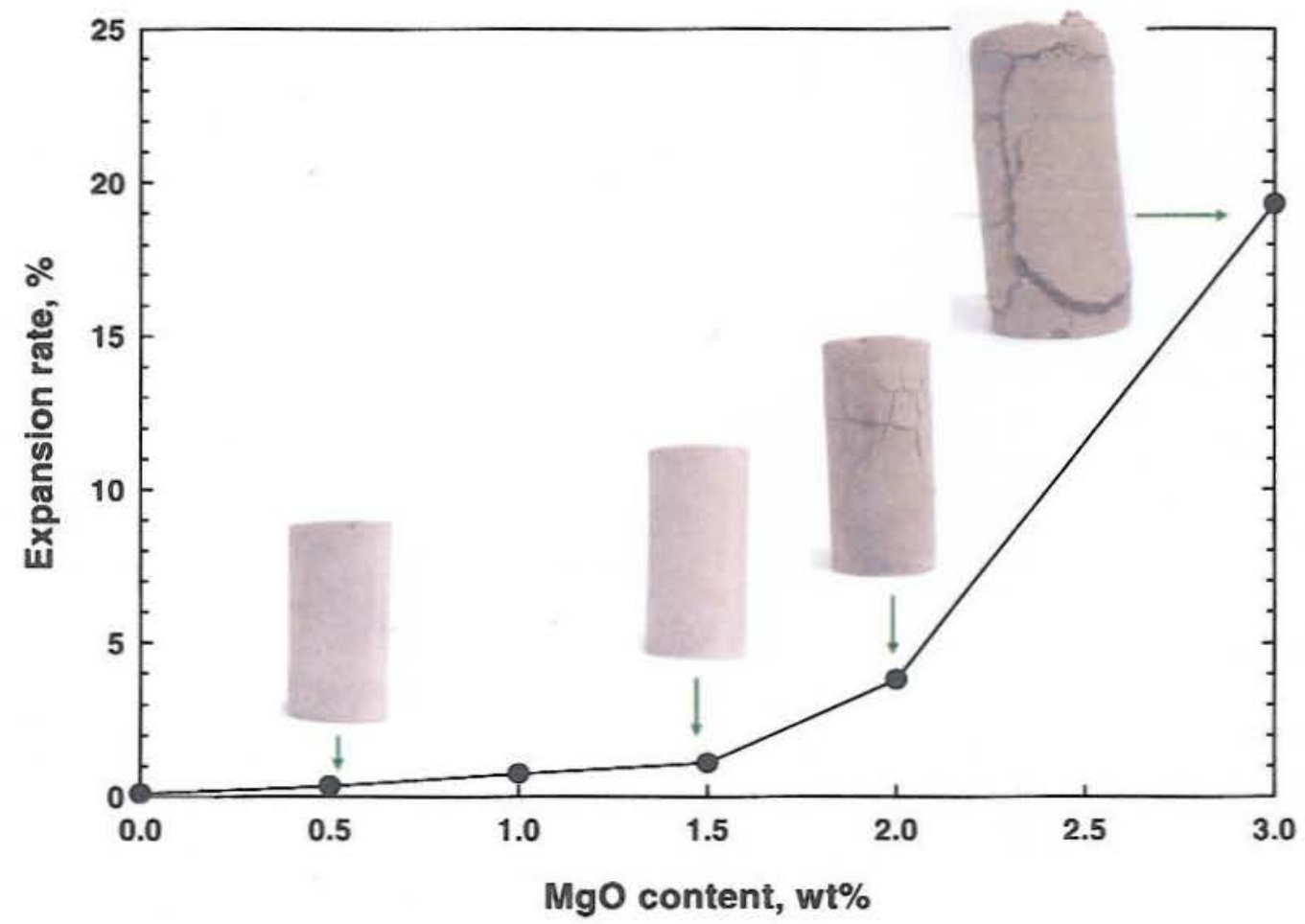

Figure 1. Changes in expansion rate of $200^{\circ} \mathrm{C}$-autoclaved SSASC specimens as a function of $\mathrm{MgO}$ content under 300 psi pressrue. 


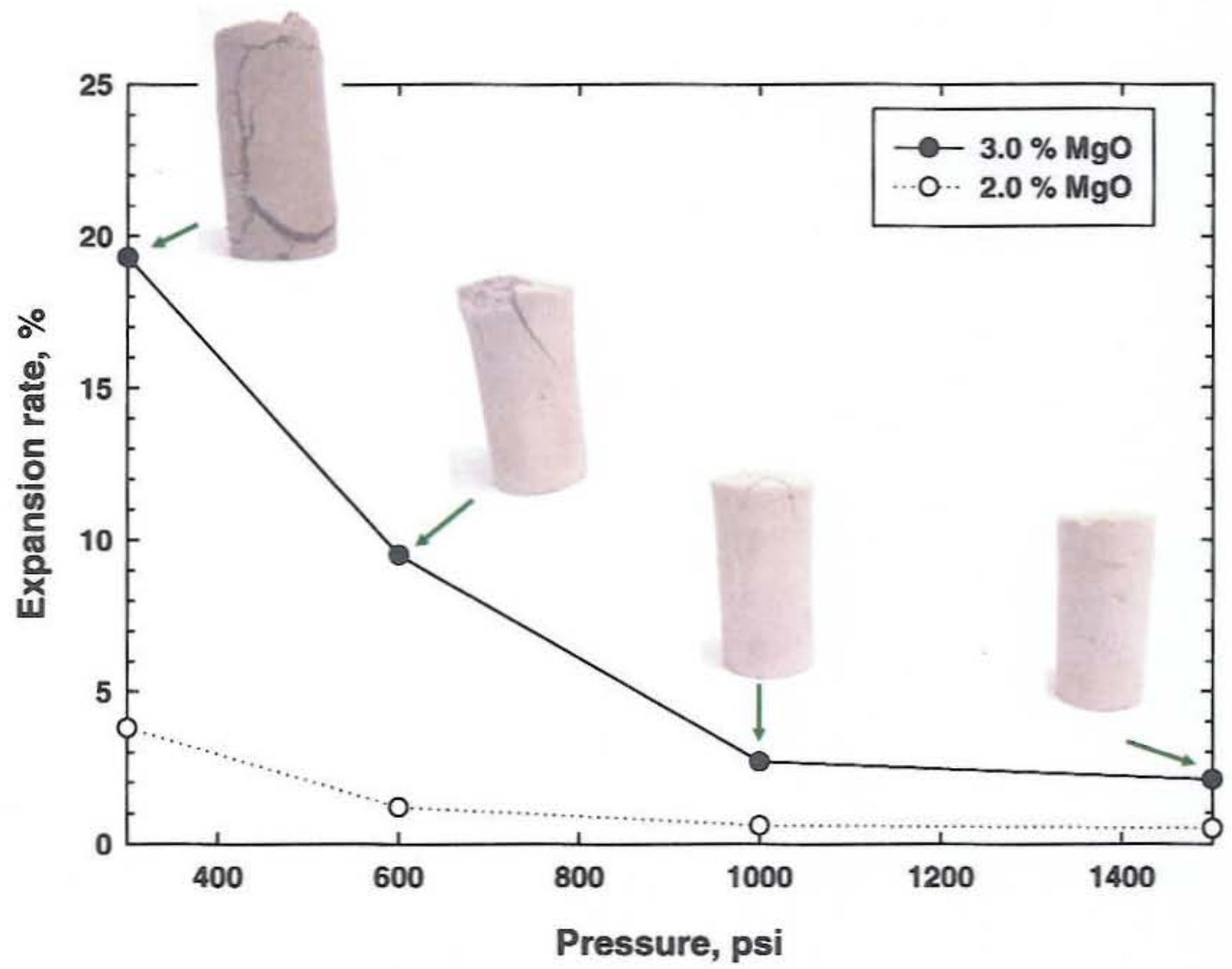

Figure 2. Changes in expansion rate of $2.0 \%$ and $3.0 \% \mathrm{MgO}$-incorporated specimens as a function of pressure, ranging from 300 psi to 1500 psi. 


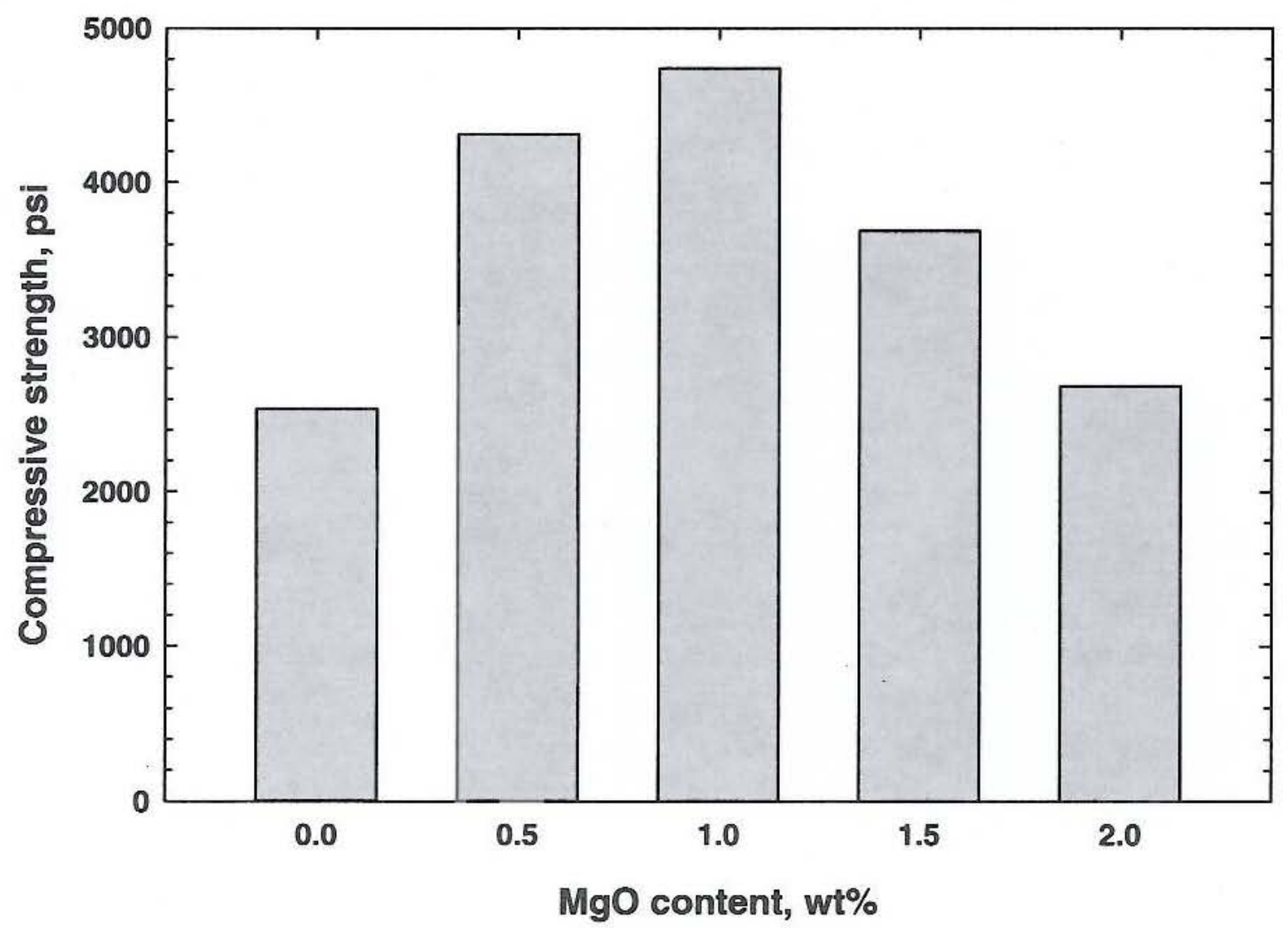

Figure 3. Compressive strength of SSASC specimens containing 0, 0.5, 1.0, 1.5, and $2.0 \% \mathrm{MgO}$ after autoclaving at $200^{\circ} \mathrm{C}$ under pressure of $300 \mathrm{psi}$. 


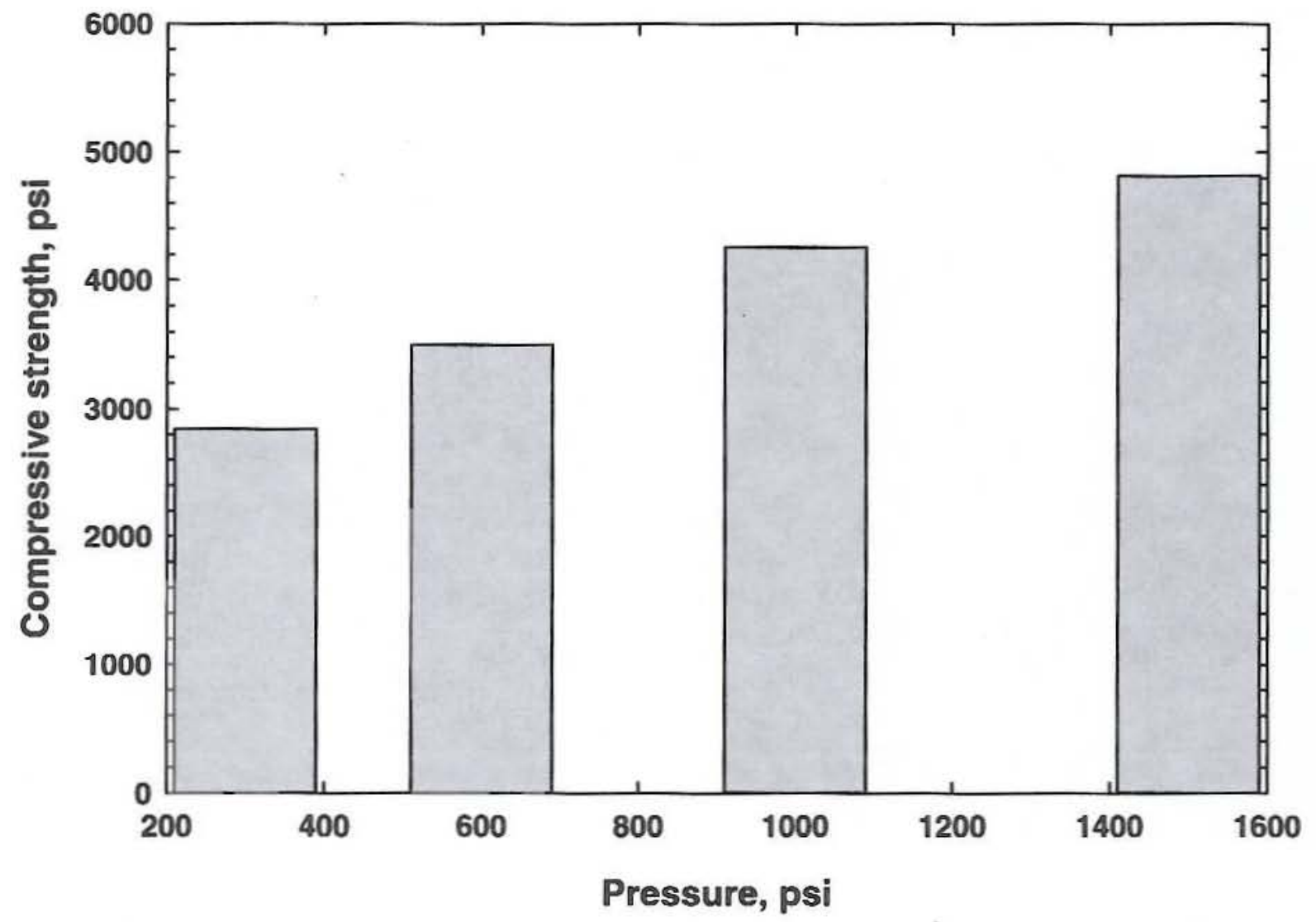

Figure 4. Compressive strength of $2.0 \% \mathrm{MgO}$ specimens made under $300,600,1000$, and 1500 psi pressures. 


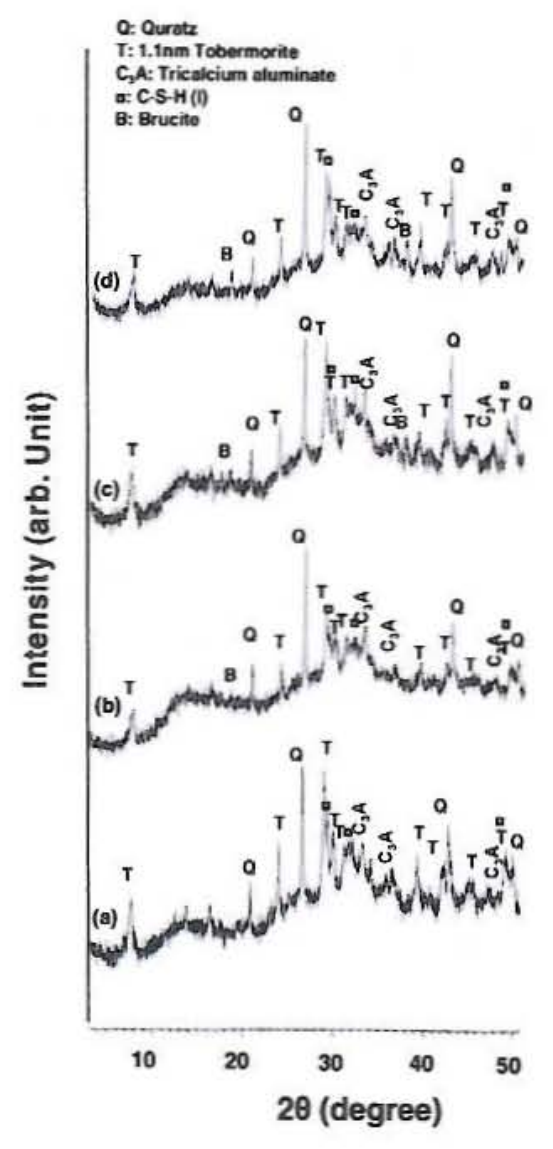

Figure 5. XRD patterns for $200^{\circ} \mathrm{C}$-autoclaved SSASC specimens containing $0 \%$ (a), $1 \%$ (b), $2 \%$ (c), and $3 \%$ (d) of $\mathrm{MgO}$. 

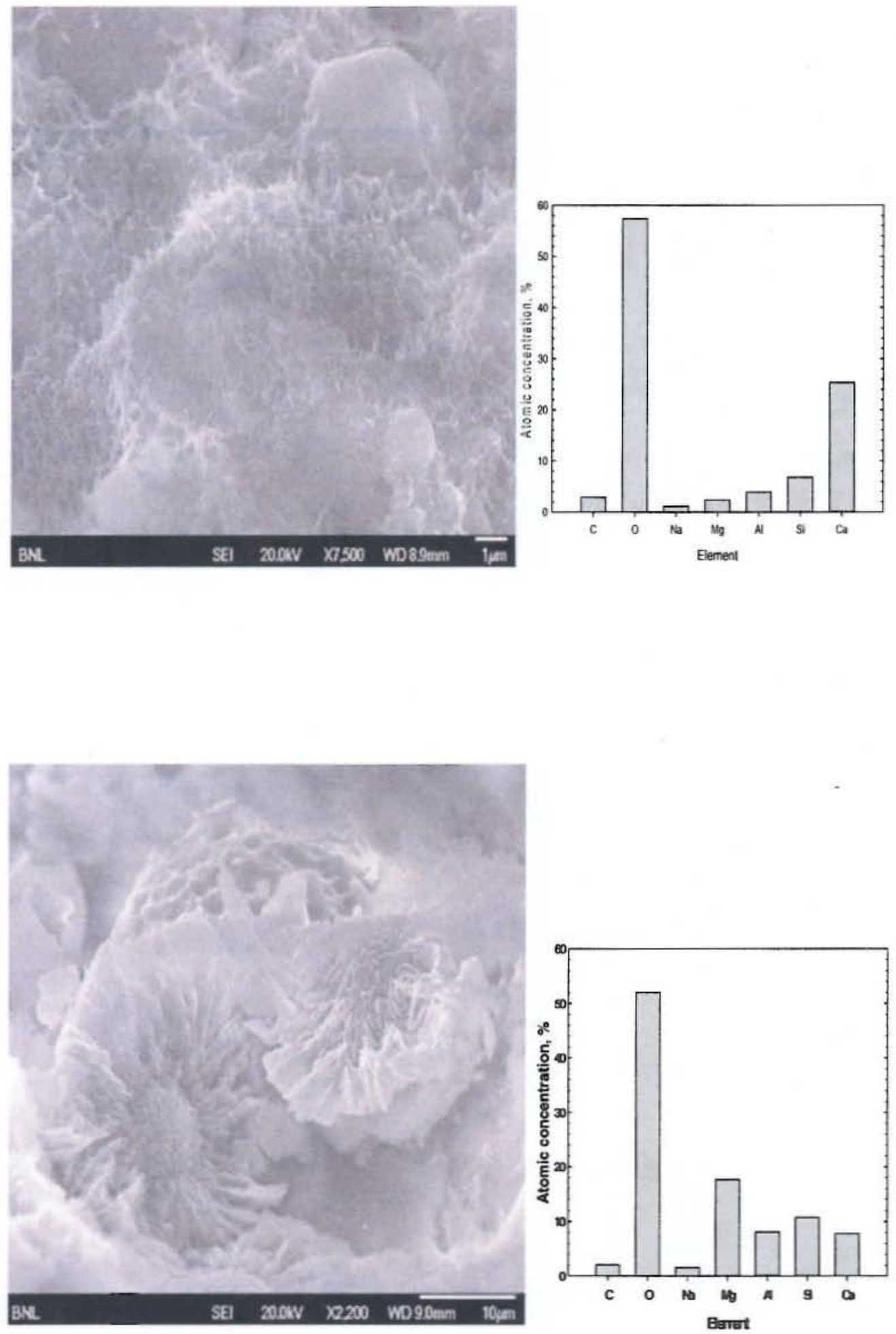

Figure 6. SEM image coupled with EDX atomic composition for fracture surfaces of $200^{\circ} \mathrm{C}$-autoclaved SSASC specimens without (top) and with $\mathrm{MgO}$ (bottom). 


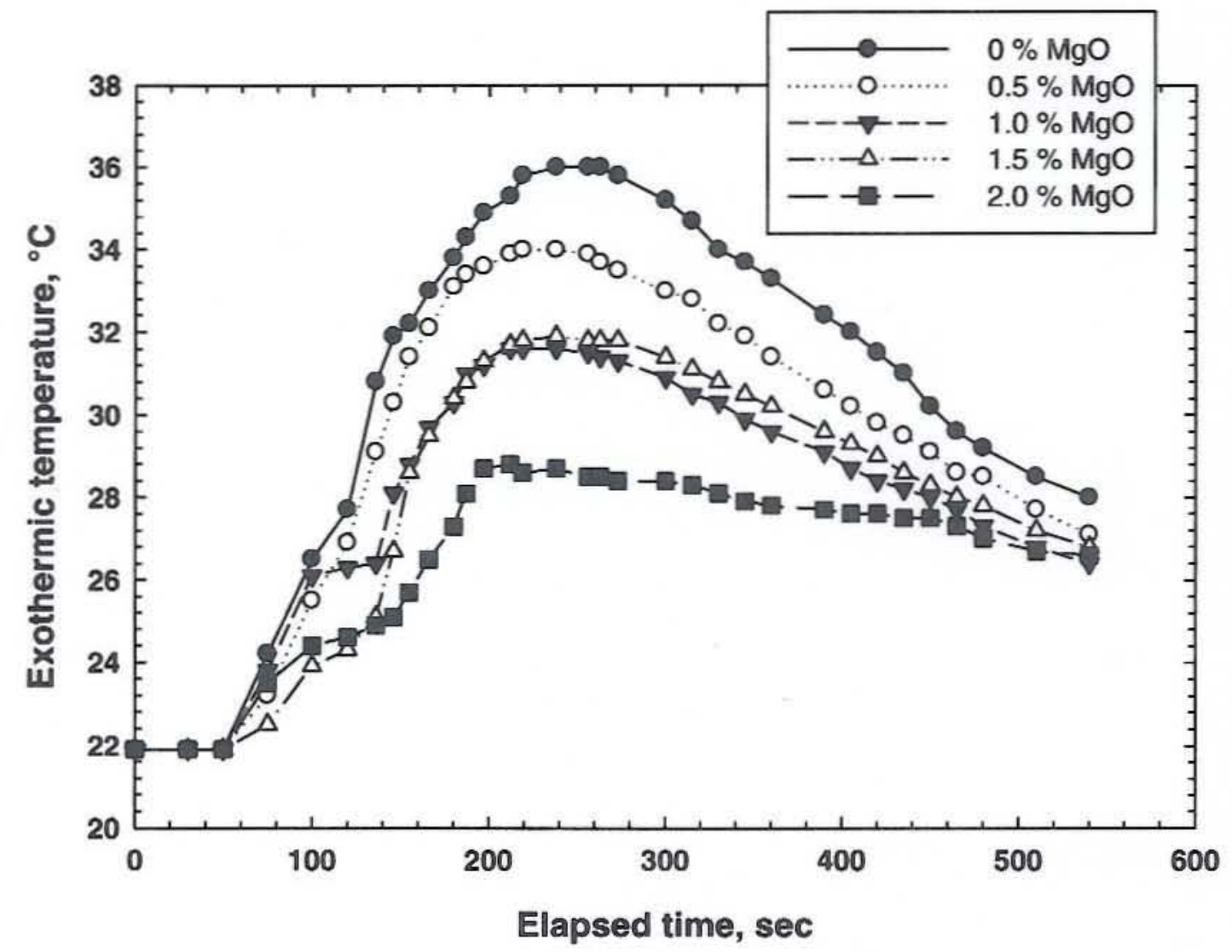

Figure 7. In-situ exothermic temperature vs. elapsed time for autoclaved $0,0.5,1.0,1.5$, and $2.0 \% \mathrm{MgO}$-containing SSASC specimens heated at $200^{\circ} \mathrm{C}$ after beginning impregnation with water. 


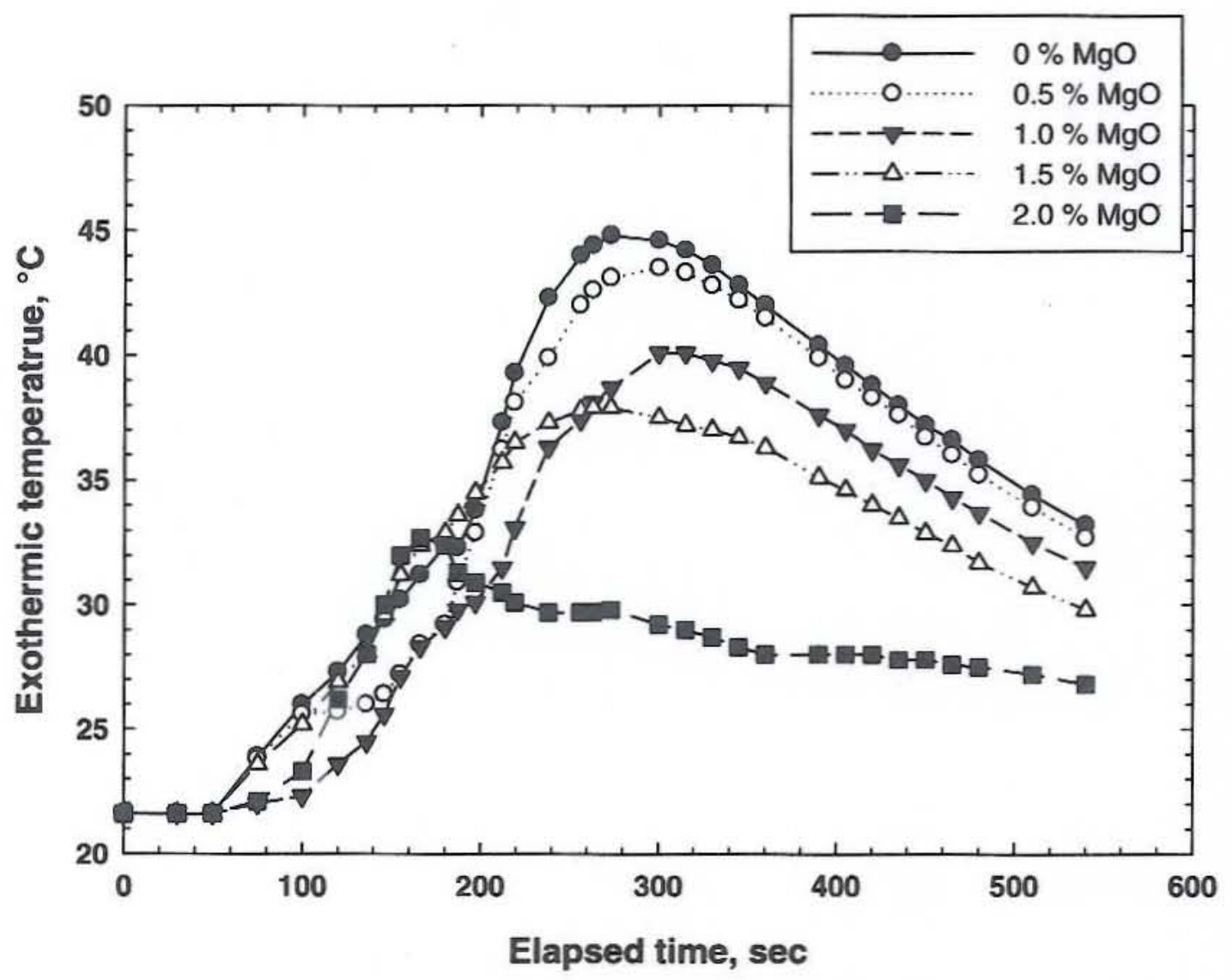

Figure 8. Comparison of exothermic peak temperatures for $250^{\circ} \mathrm{C}$-heated $0,0.5,1.0,1.5$, and $2.0 \% \mathrm{MgO}$-containing SSASC specimens after water impregnation. 
